\title{
Hedgehog hopes lifted by approval... and stung by failure
}

The US Food and Drug Administration's recent approval of Curis/Genentech's Erivedge (vismodegib), is a "watershed event" for the small biotech, according to San Francisco-based RBC Capital Markets biotech analyst Jason Kantor. The approval is all the more notable because it was based on a single-arm, phase 2 study (Nat. Biotechnol. 29, 957, 2011). The drug shrank lesions in $43 \%$ of the $\sim 100$ patients enrolled, for a median duration of 7.6 months. For the S. San Francisco, California-based Genentech, now wholly owned by Roche, the first-in-class compound for otherwise untreatable basal cell carcinoma is unlikely to become one of its bigger products.

News of the approval in late January clashed with a trial failure. Infinity, based in Cambridge, Massachusetts, announced it was stopping its phase 2 trials in pancreatic cancer with Hedgehog pathway inhibitor saridegib for lack of efficacy. The two drugs in question, however, represent two substantively different mechanisms. "There are at least two possible mechanisms of Hedgehog pathway involvement in tumorigenicity and cancer growth," says Daniel R. Passeri, president and CEO of Cambridge, Massachusetts-based Curis.

The Hedgehog pathway plays a key role in embryonic development. Its dysregulationeither due to mutations and/or as a result of ligand-dependent means - can contribute to tumor growth and survival. In the first cancer-forming mechanism, tumors are driven by a Hedgehog mutation and subsequently depend on upregulated Hedgehog to survive. "In this case, the tumors are addicted to the signaling pathway," says Passeri. Erivedge binds to, and inhibits, the transmembrane protein Smoothened, which is a key player in Hedgehog signal transduction. Erivedge's success elegantly illustrates the power of tackling the cancer cells' addiction to Hedgehog. Unfortunately, only a few other cancers, including rhabdomyosarcoma and meduloblastoma, are known to follow a similar path.

The second mechanism by which Hedgehog is involved in tumor growth is its upregulation through ligand-dependent signaling from the tumor itself or the surrounding microenvironment. Disrupting that signaling is the approach taken by Infinity with saridegib. Infinity's results contrast starkly with those obtained by Curis/Genentech. Patients taking gemcitabine with saridegib did noticeably worse than those on the standard treatment gemcitabine and placebo. "That's a surprising result that we now need to analyze carefully," says Julian Adams, Infinity's president of R\&D, adding that pancreatic cancer is a notoriously tough indication.

Others are not entirely surprised at Infinity's results. Although the ligand-dependent upregulation of the Hedgehog pathway is well documented, "We have not seen one indication yet where compounds affecting ligand-dependent signaling have worked," says Mani Mohindru, an analyst at San Francisco-based ThinkEquity. She also points out that, to date, all Hedgehog pathway inhibitors work by inhibiting Smoothened.

Infinity hasn't thrown in the towel yet on saridegib. Two additional phase 2 trials are going forward in chondrosarcoma and myelofibrosis, neither of which is thought to be mutation-driven.

A slew of companies, among them Novartis of Basel, Pfizer of New York, Bristol-Meyers Squibb in collaboration with Exelixis, and Millennium with Takeda are pursuing Hedgehog signaling pathway inhibitors. All are currently in early development (Table 1 ).

Erivedge, meanwhile, will soon be tested in other malignancies. "Genentech and the National Cancer Institute are doing a broad swath survey to see where the signal may be observed and follow that with a rationally designed clinical trial," says Curis' Passeri. Over 20 trials are ongoing in multiple indications, using different drug combinations and dosing.

"The hope," Passeri says, "is to gain insight on where [Erivedge] has therapeutic application outside of the mutation-driven cancers."

Malorye Allison, Acton, Massachusetts

Table 1 Companies developing sonic Hedgehog signaling inhibitors

\begin{tabular}{llll}
\hline Lead company & Drug & Indication & Stage \\
\hline Genentech & Erivedge & Basal cell carcinoma & Approved \\
\hline Novartis & LDE225 & Basal cell carcinoma & Phase 2 \\
& LEQ506 & Solid tumors & Phase 1 \\
\hline Infinity & Saridegib & $\begin{array}{l}\text { Bone cancer/myelofibrosis } \\
\text { Basal cell carcinoma/ head and } \\
\text { neck cancer }\end{array}$ & Phase 2 \\
& Phase 1 & Phase 1 \\
\hline Bristol-Meyers Squibb & BMS-833923 & Cancer & Phase 1 \\
\hline Pfizer & PF-04449913 & Hematologic cancer, solid tumors & \\
\hline Source: BioMedTracker/Sagient Research & &
\end{tabular}

\section{IN their words}

"I personally think the chances are almost zero." Duke University's P. Murali Doraiswamy, an Alzheimer's expert, speculates on clinical trials of Lilly's monoclonal antibody, solanezumab, currently in phase 3. For the patients in the trial, who already show symptoms, the drug may be too late, he believes. (Reuters, 1 February 2012)

"I've started companies in the past, and I've just never seen anything like this." Louis C. Cantley serial bioentrepreneur and co-founder of Agios with Craig B. Thompson, now President of
Rockefeller University. Thompson is being sued by his former employer, the Leonard and Madlyn Abramson Family Cancer Center of Philadelphia, which claims he "absconded with the fruits of the Abramson largess" when he formed Agios without informing the institute, costing it $\$ 1$ billion in lost proceeds. (New York Times, 5 February 2012)

"We are now in new territory, and I'm not sure whether the process is clear from here." Joern Aldag, CEO of Amsterdam Molecular Therapeutics
(AMT), on learning that the European Commission had not gone along with the European Medicines Agency's Committee for Human Medicinal Product's (CHMP) decision to deny marketing authorization for the company's gene therapy, Glybera (alipogene tiparvovec). AMT had petitioned the EU's Standing Committee to send Glybera back to CHMP for consideration, based on the fact that there is no therapy for the condition (lipoprotein lipase deficiency) and no safety concerns. (BioWorld, 4 January 2012) 


\section{Erratum: Reinventing clinical trials}

Malorye Allison

Nat. Biotechnol. 30, 41-49 (2012); published online 9 January 2012; corrected after print 11 May 2012

In the version of the article originally published, the ExoInTouch product being used by Pfizer in its virtual trial for overactive bladder (OAB) is eDiary, not Recruit, which allows patients to report through mobile phone or internet portals. The Recruit technology is being used in other studies. The text references to Recruit have been replaced with an explanation of eDiary. Instead of "new technology to recruit patients faster and in a more standardized fashion," the text now reads, "new technology to allow home-based clinical trial data reporting." Instead of "Recruit' text messaging technology in a pilot study" for Detrol, the text now reads, "eDiary' tool in a Phase 4 trial, called Research on Electronic Monitoring of OAB Treatment Experience." Additional explanation has been added, including "Patients can respond to simple questionnaires (Fig. 3) via their mobile phones or home computers. If they delay in responding, a reminder can be sent." And for space reasons, other text relating to Recruit, "The tool is integrated with Pfizer's volunteer database and allows immediate text message-based communication and assessment of a subject's suitability within 5-10 min" and "It can also be used to send protocol-specific messages to patients already enrolled in trials" was deleted. In addition, it should have been noted that Eric Westin, who was interviewed while senior director of Lilly Oncology, had left the company. The errors have been corrected in the HTML and PDF versions of the article.

\section{Erratum: Parallel genome universes}

Tom Misteli

Nat. Biotechnol. 30, 55-56 (2012); published online 9 January 2012; corrected after print 7 June 2012

In the version of this article initially published, the volume number and year of reference 2 should have been 30 and 2012 , and not 29 and 2011 , respectively. The errors have been corrected in the HTML and PDF versions of the article.

\section{Erratum: BASF moves GM crop research to US}

Lucas Laursen

Nat. Biotechnol. 30, 204 (2012); published online 7 March 2012; corrected after print 7 June 2012

In the version of this article initially published, BASF's Amflora, a genetically modified potato for industrial use, was mistakenly said to be blight resistant when it is not. The error has been corrected in the HTML and PDF versions of the article.

\section{Erratum: In Their Words}

Nat. Biotechnol. 30, 203 (2012); published online 7 March 2012; corrected after print 7 June 2012

In the version of this article initially published online, Craig Thompson was incorrectly identified as the president of Rockefeller University. He is the president of Memorial Sloan-Kettering Cancer Center in New York. The error has been corrected for the PDF version of this article.

\section{Corrigendum: Performance comparison of whole-genome sequencing platforms}

Hugo Y K Lam, Michael J Clark, Rui Chen, Rong Chen, Georges Natsoulis, Maeve O’Huallachain, Frederick E Dewey, Lukas Habegger, Euan A Ashley, Mark B Gerstein, Atul J Butte, Hanlee P Ji \& Michael Snyder

Nat. Biotechnol. 30, 78-82 (2012); published online 18 December 2011; corrected after print 7 June 2012

In the version of this article initially published, the accession code to obtain raw sequence data was given as SRA045736.2; the correct code is SRA045736. The error has been corrected in the HTML and PDF versions of the article.

\section{Corrigendum: Performance comparison of benchtop high-throughput sequencing platforms}

Nicholas J Loman, Raju V Misra, Timothy J Dallman, Chrystala Constantinidou, Saheer E Gharbia, John Wain \& Mark J Pallen Nat. Biotechnol. 30, 434-439 (2012); published online 22 April 2012; corrected online 23 April 2012; corrected after print 7 June 2012

In the version of this article initially published online, in the Online Methods "Ion Torrent Sequencing" section, the sentence beginning with "Ten milligrams of this DNA was fragmented with a Bioruptor instrument...." should have read "Ten micrograms..." and in the "454 GS Junior sequencing" section, "(500 total)” should have read "(500 ng total)." The errors have been corrected in the PDF and HTML versions of this article. 